\title{
'A Healthy CIT': An Investigation into Student Health Metrics, Lifestyle Behaviours and the Predictors of Positive Mental Health in an Irish Higher Education Setting
}

\author{
Andrea Bickerdike *, Joan Dinneen and Cian O'Neill(1) \\ Department of Sport, Leisure \& Childhood Studies, Cork Institute of Technology, Cork T12 P928, Ireland; \\ joan.dinneen@cit.ie (J.D.); cian.oneill@cit.ie (C.O.) \\ * Correspondence: andrea.bickerdike@cit.ie
}

Received: 28 September 2019; Accepted: 4 November 2019; Published: 6 November 2019

\begin{abstract}
Higher Education Institutions (HEIs) are potent health promotion settings, uniquely positioned to aid societal efforts to combat non-communicable diseases (NCDs). International evidence suggests that health metrics and lifestyle behaviours of higher education students are sub-optimal, yet a dearth of contemporary Irish data exists. This study aimed to examine sex differences in student lifestyle behaviours and identify significant predictors of positive mental health in an Irish HEI setting. An online questionnaire instrument distributed to all registered students $(n=11,261)$ gathered data regarding a multitude of health and lifestyle domains. Many items were adapted from previous Irish research. Further validated scales included the Alcohol Use Disorders Identification Test (AUDIT), Mental-Health Index 5 (MHI-5) and the Energy and Vitality Index (EVI). Self-reported height/body mass were also recorded. In total, 2267 responses were analysed $(51.7 \%$ female, $48.3 \%$ male). Both sexes demonstrated poor sleeping patterns, hazardous drinking and sub-optimal fruit and vegetable intake. The calculated prevalence of overweight/obesity was $38.2 \%$. Both sexes underestimated obesity. Males underestimated and females overestimated overweight. Males displayed riskier behavioural patterns with regard to illicit substances, drinking, and sexual partners. Females reported greater psychological distress. Multivariate linear regression identified 8 variables as predictors of positive mental health, accounting for $37 \%$ of the variance in EVI scores. In conclusion, HEI students would benefit from sex-specific multi-level health promotion initiatives to remove macro-level barriers to healthier lifestyles.
\end{abstract}

Keywords: university students; health; gender; health promotion; health behaviours; lifestyle; healthy universities; BMI; mental health

\section{Introduction}

Unhealthy lifestyles increase the risk of non-communicable diseases (NCDs) such as cardiovascular disease, respiratory disorders, diabetes and cancers [1]. In 2016, NCDs accounted for $71 \%$ of worldwide deaths and $91 \%$ of population deaths in Ireland [2]. Due to the deleterious physiological and economic effects of NCDs, enabling healthy behaviours throughout the lifespan is a fundamental priority of the Irish Government's health promotion strategy [3].

In this regard, higher education may constitute a cost-effective setting for the implementation of health education initiatives [4]. It is a uniquely transitional life stage where a multitude of lifestyle behaviours and social experiences are interwoven within the culture and built environment of a single Higher Education Institution (HEI) setting [5]. However, financial scarcity and academic stressors [6] 
experienced within a newly autonomous environment can result in students engaging in risk-taking behaviours [7] that are associated with the quintessential 'college lifestyle'.

In addition, the 'Freshman 15' (an alleged weight gain of 15 pounds or $6.8 \mathrm{~kg}$ during a student's first year of higher education) has remained a widely-cited phenomenon, despite a lack of objective verification [8]. A recent meta-analysis incorporating data from 5549 higher education students reported that the overall mean gain in body mass was 3 pounds $(1.36 \mathrm{~kg}), 60.9 \%$ of students gained at least some weight and 9.3\% gained the postulated 'freshman 15' [9]. In a general context, the volume of studies reporting increases in students' body mass during the first year of higher education [10-14] constitutes a worrying physiological trajectory.

Similarly, detrimental trends in body composition have also been observed over the course of a four-year academic programme in a USA university, with significant increases in students' Body Mass Index (BMI), body fat percentage and total fat mass values [15]. Using BMI as an indicator of adiposity, a study investigating overweight/obesity among HEI students across seven European countries reported prevalence ranges of between $4.6 \%$ (Bulgaria) to $18 \%$ (Denmark) among females and $12 \%$ (Lithuania) to $27.3 \%$ (Germany) among males [16]. This study also highlighted generalised misperceptions of anthropometric status; male students classified themselves as too thin whereas females perceived themselves as excessively fat [16].

HEI students also appear to exhibit sub-optimal dietary behaviours as evidenced by inadequate intake of fruit and vegetables [7,17-21] and habitual consumption of fast food during a typical week [22-24]. In particular, students who move away from home appear to consume fewer home-cooked meals [20]. Reported breakfast consumption patterns have been variable between studies. A German study reported that just over one quarter did not regularly (defined as $4-5$ per week) eat breakfast [17] whereas research conducted in the USA reported that $38.7 \%$ of students consumed breakfast less than five times per week [25]. The transition from school to university may also be a time where students become less physically active, particularly those who move residence [26]. It appears that eating and physical activity behaviours are influenced by both personal motivations and self-regulation, further complexified by the unique barriers interwoven within the campus environment and social constructs of the college lifestyle [27].

Hazardous drinking habits have been widely documented among HEI students in Ireland [28], the United Kingdom [29,30], Belgium [31], Australia [32], New Zealand [33,34], North America [35] and South Africa [36]. In addition, although the exact prevalence of drug use among young people is difficult to establish due to a scarcity of objective studies [37], illicit substance misuse has been reported among cohorts of higher education students, both in terms of prescription medications [38] as well as recreational substances [24,37]. In terms of sexual health, a casual 'hook-up' culture has been reported, with students displaying a lack of concern regarding their vulnerability to sexually transmitted infections [39].

Psychologically, inherent stressors such as extensive academic workloads, scarce finances and uncertainty regarding the future are ingrained within the very nature of the higher education experience [40]. Previous research has reported the prevalence of psychosomatic symptoms such as fatigue $(59.7 \%)$, headaches $(57.8 \%)$ and back pain $(42.7 \%)$ among a cohort of higher education students [6]. Psychological wellbeing may be further attenuated by poor sleep quality [41] which can be a normative aspect of university life [42].

From a wider socio-cultural perspective, technological advances and the emergence of mobile technologies over the past number of years may have influenced contemporary student lifestyle behaviours and parameters of wellbeing. For example, smartphone use may be associated with poorer sleep quality in a relationship mediated by depression and anxiety [43], and internet addiction has emerged as a health concern among first year university students in Turkey [44]. Social media has become ingrained within the lives of many young adults [45] and exposes users to alcohol-related content and advertising [46]. 
Traditionally, studies pertaining to student lifestyles have emphasised a particular health domain or behaviour [21]. However, it has been previously argued that health-related behaviours should not be studied in isolation but as collections that can cluster in favourable or unfavourable patterns [47]. In addition, it is possible that institution-/university-specific clustering of either 'health-promoting' or 'health-damaging' indicators exist, hence the need to establish setting-specific profiles from which to guide campus health promotion programmes [6].

Demographically, sex differences in the lifestyle behaviours of higher education students have been elicited. Males have been shown to be more physically active $[7,21,47-49]$, however greater levels of illicit drug use have also been reported [24]. Females have consistently reported greater levels of psychological stress $[6,24,47]$, but have also exhibited a tendency to consume more portions of daily fruit and vegetables [7,47]. Interestingly, traditionally accepted sex differences in drinking patterns may have changed with recent Irish research reporting a greater prevalence of hazardous drinking among females [28].

It is evident that in any effort to describe the contemporary lifestyle patterns of higher education students, sex must be considered as a demographic covariate. Secondly, lifestyles must also be considered within the cultural context of the HEI setting. Finally, ongoing research is required to document student lifestyle patterns over time. In Ireland, a designated longitudinal programme of research was recommended following the worrying lifestyle trends identified by a nationally representative study of undergraduate students [24]. However, such a multi-setting programme of research was never implemented and a relative dearth of contemporary data exists.

The purpose of the current study was to explore a series of student health parameters and lifestyle behaviours within a medium-sized HEI in southern Ireland. Specific objectives focused on (1) the examination of sex-related differences across a number of health and lifestyle domains and (2) the identification of significant lifestyle predictors of positive mental health. Findings will be utilised to identify pertinent action areas for a new campus health promotion initiative (A Healthy CIT) and will be of interest to policy makers in similar institutions elsewhere.

\section{Materials and Methods}

\subsection{Study Design}

A Healthy CIT is a campus health promotion initiative at Cork Institute of Technology (CIT) that aims to maximise the health and wellbeing of all students and staff. Launched in 2016, the initiative endeavours to integrate a consideration for health and wellbeing into all aspects of the Institute's operations, in accordance with the recommendations of the Okanagan Charter for Health Promoting Universities and Colleges [50]. A Healthy CIT encompasses a designated research arm within CIT's Department of Sport, Leisure and Childhood Studies to strategically guide its future development and evaluation. Development and pilot activities are described in further detail elsewhere [51].

Data included in this study were collected as part of baseline research activities; a cross-sectional web-based health survey conducted during Semester Two (Spring) of a standard academic year. All registered students of the Institute, aged 18 and over, were eligible to participate. The study was conducted in accordance with the Declaration of Helsinki, and the protocol and questionnaire instrument were approved by the Research Ethics Committee of the host institution prior to data collection.

\subsection{Questionnaire Instrument}

A questionnaire instrument was developed consisting of 92 main items pertaining to a series of health and lifestyle domains (demographics, general health, food habits and nutrition, physical activity, alcohol, tobacco and drug use, sexual health, sleep patterns, mental health, and social media use). Many items were adapted from previous Irish research [24,52-54] to facilitate retrospective comparisons. The instrument was hosted on an online platform ('Lime Survey'). Skip-logic exposed 
participants only to relevant items based on their previous responses. Variables included in the current analyses were:

Demographics: sex, age, nationality, year of study, National Framework of Qualifications (NFQ) level ('undergraduate/taught postgraduate/postgraduate by research'), mode of study ('full time student/ part time or evening student') and area of study (later recoded by Faculty). These items were in line with previous Irish research [24,52,53].

Academic achievement during the preceding semester was self-reported on a categorical item reflecting the Institute's grade bands (less than $40 \% / 40-59 \% / 60-69 \% / 70 \%$ or above/don't know/I would rather not provide this information).

Self-reported general health was measured using a single item adapted from previous Irish research $[24,54]$ ('In general, would you say your health is') with answers on a 5-point Likert Scale: (1) 'very poor', (2), 'poor' (3) 'neither poor nor good' (4) 'good' (5) 'very good'. 'Poor' and 'very poor' categories were later combined for analysis.

Body Mass Index [BMI] was calculated from self-reported height ('What is your estimated height?) and body mass ('What is your estimated current weight?') using the standard formula: $\frac{\text { Weight }(\mathrm{kg})}{\text { Height }^{2}\left(\mathrm{~m}^{2}\right)}$. BMI weight categories were defined according to World Health Organisation criteria; $<18.5 \mathrm{~kg} / \mathrm{m}^{2}=$ underweight, $18.5-24.9 \mathrm{~kg} / \mathrm{m}^{2}=$ normal weight, $25.0-29.9 \mathrm{~kg} / \mathrm{m}^{2}=$ overweight and $\geq$ $30.0 \mathrm{~kg} / \mathrm{m}^{2}=$ obese [55].

Self-perceived weight category was measured with a single categorical item ('Which general category do you feel best describes you?'). Participants selected either 'underweight', 'normal weight', 'overweight' or 'obese'.

Daily fruit and vegetable servings were self-reported ('How many servings of fruit and/or vegetables do you eat on average every day?'). A reference description of a serving was provided as ' 3 dessert spoons of vegetables or 1 piece of fruit' [52].

Habitual breakfast consumption was measured with two items pertaining to consumption during the week ('How many days during the week do you normally eat breakfast?') and at weekends ('How many days at the weekend do you normally eat breakfast?'). Participants were required to self-report numerical values from 0-5 (weekdays) or 0-2 (weekends).

Barriers to physical activity were elicited with a single categorical item sourced from previous Irish research [54] ('What would you say is the main reason why you are not (more) physically active at this time?'). Participants were provided with seven potential barriers, as well as the option to specify an additional 'other' barrier. A ninth barrier ('I feel that I may be taking too much exercise or overtraining') was added to this item specifically for the current study.

Physical activities (type) during the 7 days prior to survey participation were elicited using three newly-devised items each pertaining to (i) light, (ii) moderate and (iii) vigorous intensity activities respectively. These items were formulated based on the structure of the International Physical Activity Questionnaire [56] and previous Irish research [24]. For each item, participants were provided with a reference description of the relative intensity. A list of activities and popular sports was then provided, based on sample activities listed in the Irish physical activity guidelines [57] as well as the 2015 report of the Irish Sports' Monitor [58]. Participants were instructed to select all sporting, routine or occupational activities (if any) that they had participated in.

Physical Activity (volume) during the 7 days prior to survey participation was quantified using a newly-devised item that required participants to enter (i) the frequency and (ii) duration (in minutes) of each session of light, moderate and vigorous physical activity undertaken (if applicable). This enabled the calculation of total volume of each respective category in minutes per week (frequency $x$ duration). The primary variable of interest was whether students were sufficiently physically active according to Irish National Physical Activity Guidelines for adults [57]. A participant was deemed to have met the guidelines if their combined volume of vigorous and moderate activity reached a threshold of $150 \mathrm{~min}$ of moderate intensity activity. For the purposes of these calculations, 1 minute of vigorous intensity 
activity was considered to be equivalent to 2 min of moderate intensity activity, as outlined in the aforementioned Irish National Physical Activity Guidelines document [57].

Daily sitting time was measured with a newly devised ordinal item ('During an average day at college for you, how many hours do you usually spend sitting down? For example, sitting at a desk, driving a car, sitting in a lecture etc.') with a 6-point scale ranging from 'less than 1 hour' to 'more than $5 \mathrm{~h}^{\prime}$.

Alcohol consumption patterns were evaluated using the Alcohol Use Disorders Identification Test (AUDIT), a validated 10-item instrument to detect problem drinking [59]. Possible scores range from 0 to 40 with scores between $8-15$ warranting advice regarding reduction of hazardous drinking, scores between 16 and 19 suggestive of problem drinking and scores of 20 or more justifying further evaluation for dependence on alcohol $[29,59]$. The instrument is comprised of a series of subdomains specifically measuring hazardous alcohol use (also referred to as the 'AUDIT-C' scale) (items 1-3), dependence symptoms (items 4-6) and harmful alcohol use (items 7-10).

Tobacco smoking items were sourced from previous Irish research $[24,52]$ and elicited current smoking status 'Do you smoke tobacco now?', with answer options being 'no', 'yes regularly' or 'yes occasionally (usually less than 1 per day').

Cannabis/marijuana use was measured using the following item; 'On how many occasions, if any, have you used marijuana (grass, pot) or cannabis (hash, hash oil)?' [52]. Frequency of use was reported on a 7-point Likert scale (never, once or twice, 3-5 times, 6-9 times, 10-19 times, 20-39 times, 40 times or more) with three separate sub-items to distinguish between (i) lifetime use, (ii) use within the 12 months prior to the survey and (iii) use within the 30 days prior to the survey.

Illicit Substance use was measured by providing participants with a list of recreational substances (plus their colloquial street names). For each substance, they were requested to report their frequency of use on a 4-point Likert scale ('never', 'yes but not in past 12 months', 'once or twice in the past 12 months', ' 3 or more times in the past 12 months'). This item was adapted directly from previous research [24] with the addition of 'head-shop products'. The accompanying street names were verified by consultation with local addiction services of the Irish Health Service Executive. The Likert scale was later dichotomised (lifetime use yes/no) for analysis by sex.

Sexual health items were sourced from the Trinity College Survey for Sexual Health, as cited in previous Irish research [24]. Items elicited sexual orientation, sexual activity status, age of first intercourse, use of drugs and/or alcohol prior to previous intercourse, methods of sexually transmitted infection (STI) protection, history of STI diagnosis, morning-after pill use and (self-reported) total number of sexual partners.

Self-rated mental health was measured with a single item ('How would you rate your own mental health?') [24] with an identical 5-point response scale as outlined for general health above.

Positive and negative mental health were measured using the Energy and Vitality Index (EVI) and the Mental Health Index-5 (MHI-5) respectively, both of which are subscales of the Short-Form Health Survey (SF-36) [60].

Psychological stress was evaluated with an item from previous Irish research that listed 11 stressors of specific relevance to this cohort (issues such as academic workload, finances and relationships plus an option to select 'other') [24]. One additional stressor was included ('social media') for the current study. Participants were requested to indicate their perception of each stressor on a four-point scale ('highly stressed', 'often stressed', 'not often stressed' or 'never stressed').

Recent sleep quality was self-reported on a single item ('During the past 30 days, how would you rate your sleep quality overall?') with identical 5-point response scale as outlined for general and mental health ratings above. This item was adapted from the sleep quality component of the Pittsburgh Sleep Quality Index [61].

Habitual sleep duration was measured with an item that asked participants to quantify their sleep duration ('On average, how much sleep do you get?') both on weekdays and at the weekends [52]. Answers were provided on a 7-point Likert scale ranging from 'less than $4 \mathrm{~h}$ ' to ' $9 \mathrm{~h}$ or more'. 
Social media items ascertained the platforms used, as well as the average time spent on social media on weekdays and at weekends. These items were adapted from previous Irish research involving a cohort of medical students [62]. Further newly devised items established whether pictures were posted within 30 days of the survey and if so, whether such pictures were alcohol-related (oneself or another consuming or being around alcohol).

\subsection{Survey Implementation and Data Collection Procedure}

In line with previous research [24,63], the survey was incentivised with entry into a draw to win an iPad. An initial email invitation, containing a direct hyperlink to the questionnaire was distributed to 11,261 registered CIT student email addresses. This email described the purpose and scope of the study, nature of the questionnaire and assured all participants that participation was voluntary and responses were fully anonymised. Participants could also 'opt-out' of any further correspondence, if desired, and those who opted out received no further contact. The survey remained accessible for a 23-day period. A total of three reminder emails were sent to all those who had not completed the questionnaire at days 7, 14 and 20, respectively. The survey was reactivated for a 7-day period following cessation of the Institute's end of semester examinations.

\subsection{Statistical Analysis}

Data were exported directly to Microsoft Excel (Microsoft Inc., Redmond, WA, USA) and IBM Statistical Package for the Social Sciences [SPSS] Version 25.0 (IBM Inc., Armonk, NY, USA). Data cleaning encompassed a review of all variables to examine the nature of outlier values and missing data. In the current paper, data are presented relative to the number of valid responses received to each applicable item; for the purpose of regression analyses, a 'pairwise' method of exclusion was applied.

Categorical data were analysed by establishing relative frequencies. Where applicable, specified responses initially placed within the 'other' category were re-coded to the relevant categorical option. Missing data points due to survey skip logic were excluded from the relative frequencies reported within each health domain but included as valid (coded 0) for three specific variables in the linear regression model (outlined further below). Numeric data were described using means/standard deviations or median/interquartile ranges as appropriate. Sex differences were elicited using Chi Squared Tests for Independence (for categorical variables) and Mann Whitney U Tests as applicable. Alpha level of significance was set at 0.05 .

Physical activity volume was derived based on reported frequency and duration during the 7 days prior to data collection, as outlined above. Self-reported height and body mass values were first mathematically converted (where necessary) from imperial values to metric equivalents and then used to determine BMI. Cohen's Kappa was calculated to ascertain the relative level of agreement between calculated and perceived BMI category. Validated scales were scored as per relevant instruction manuals. Multivariate linear regression was used to identify significant predictors of positive mental health.

\section{Results}

\subsection{Response Rate and Student Demographics}

In total, 2390 responses (21.2\% response rate) were recorded on the LimeSurvey platform (www.limesurvey/org). Blank datasets $(n=121)$ were removed and two spoiled datasets were excluded at a later stage, leaving 2267 cases (20.1\% total response rate). Mean completion time recorded by the survey platform was $18.7 \mathrm{~min}$. Due to the substantial length of the questionnaire, there was a progressive decline in responses observed as well as variability in response numbers to each item. A total of 1541 participants proceeded to the final section of the questionnaire ( $68.0 \%$ of initial sample retained, $13.7 \%$ overall response rate). Individual item valid response rates ranged from a maximum of $100 \%(n=2267)$ to a minimum of $63.9 \%(n=1449)$. 
Just over fifty-one percent $(51.7 \%)$ of those who initially responded were female $(n=1173)$ and $48.3 \%$ were male $(n=1094)$. Reported ages ranged from a minimum of 18 to a maximum of 65 years old however the majority $(68.9 \%, n=1560)$ were aged between 18 and 23 . There was no significant association between sex and progressing to the final section of the questionnaire instrument $[\chi 2(1$, $n=2267)=0.64, p=0.43$ Phi 0.02]. Table 1 presents each demographic variable by sex.

Table 1. Demographic Characteristics of Participants by Sex.

\begin{tabular}{|c|c|c|c|c|c|c|c|}
\hline \multirow{2}{*}{ Demographic Variable } & \multicolumn{2}{|c|}{ Total } & \multicolumn{2}{|c|}{$\mathbf{M}$} & \multicolumn{2}{|c|}{$F$} & \multirow{3}{*}{$p$-Value } \\
\hline & $n$ & $\%$ & $n$ & $\%$ & $n$ & $\%$ & \\
\hline Sex & 2267 & & 1094 & 48.3 & 1173 & 51.7 & \\
\hline \multicolumn{8}{|l|}{ Age } \\
\hline $18-20$ years \# & 806 & 35.6 & 357 & 32.7 & 449 & 38.4 & 0.003 \\
\hline $21-23$ years & 754 & 33.3 & 362 & 33.1 & 392 & 33.5 & \\
\hline 24 years and older \# & 703 & 31.1 & 374 & 34.2 & 329 & 28.1 & \\
\hline Total & 2263 & & 1093 & & 1170 & & \\
\hline \multicolumn{8}{|l|}{ Mode of study } \\
\hline Undergraduate & 1891 & 90.2 & 907 & 89.4 & 984 & 91.0 & 0.22 \\
\hline Postgraduate (Taught) & 133 & 6.3 & 66 & 6.5 & 67 & 6.2 & \\
\hline Postgraduate (Research) & 72 & 3.4 & 42 & 4.1 & 30 & 2.8 & \\
\hline Total & 2096 & & 1015 & & 1081 & & \\
\hline \multicolumn{8}{|l|}{ Registration status } \\
\hline Full-time & 1918 & 88.4 & 919 & 87.6 & 999 & 89.2 & 0.28 \\
\hline Part-time or evening & 251 & 11.6 & 130 & 12.4 & 121 & 10.8 & \\
\hline Total & 2169 & & 1049 & & 1120 & & \\
\hline \multicolumn{8}{|l|}{ Faculty $^{* *}$} \\
\hline Business \& Humanities \# & 941 & 42.9 & 327 & 30.8 & 614 & 54.2 & $<0.0005$ \\
\hline Engineering \& Science \# & 922 & 42.0 & 579 & 54.6 & 343 & 30.3 & \\
\hline Crawford College of Art \& Design \# & 169 & 7.7 & 59 & 5.6 & 110 & 9.7 & \\
\hline Cork School of Music \# & 98 & 4.5 & 37 & 3.5 & 61 & 5.4 & \\
\hline National Maritime College of Ireland \# & 51 & 2.3 & 49 & 4.6 & 2 & 0.2 & \\
\hline Other \# & 13 & 0.6 & 10 & 0.9 & 3 & 0.3 & \\
\hline Total & 2194 & & 1061 & & 1133 & & \\
\hline \multicolumn{8}{|l|}{ Year Group (undergraduates) } \\
\hline 1 & 642 & 32.6 & 298 & 31.7 & 344 & 33.5 & 0.49 \\
\hline 2 & 510 & 25.9 & 256 & 27.2 & 254 & 24.7 & \\
\hline 3 & 464 & 23.6 & 213 & 22.7 & 251 & 24.4 & \\
\hline 4 & 338 & 17.2 & 165 & 17.6 & 173 & 16.8 & \\
\hline Other & 13 & 0.7 & 8 & 0.9 & 5 & 0.5 & \\
\hline Total & 1967 & & 940 & & 1027 & & \\
\hline \multicolumn{8}{|l|}{ Year Group (postgraduates) } \\
\hline 1 & 97 & 47.5 & 47 & 43.5 & 50 & 52.1 & 0.06 \\
\hline 2 & 49 & 24.0 & 22 & 20.4 & 27 & 28.1 & \\
\hline 3 & 20 & 9.8 & 11 & 10.2 & 9 & 9.4 & \\
\hline 4 & 23 & 11.3 & 16 & 14.8 & 7 & 7.3 & \\
\hline 5/6/Other \# & 15 & 7.4 & 12 & 11.1 & 3 & 3.1 & \\
\hline Total & 204 & & 108 & & 96 & & \\
\hline \multicolumn{8}{|l|}{ Nationality } \\
\hline Irish \# & 1937 & 89.2 & 954 & 91.0 & 983 & 87.5 & \\
\hline UK & 30 & 1.4 & 16 & 1.5 & 14 & 1.2 & 0.006 \\
\hline Other European \# & 141 & 6.5 & 48 & 4.6 & 93 & 8.3 & \\
\hline Other & 64 & 2.9 & 30 & 2.9 & 34 & 3.0 & \\
\hline Total & 2172 & & 1048 & & 1124 & & \\
\hline \multicolumn{8}{|l|}{$\begin{array}{l}\text { Academic Achievement (undergraduates } \\
\text { only) }\end{array}$} \\
\hline Less than $40 \%$ & 11 & 0.6 & 6 & 0.6 & 5 & 0.5 & 0.02 \\
\hline $40-59 \%$ \# & 464 & 23.9 & 253 & 27.2 & 211 & 20.9 & \\
\hline $60-69 \%$ & 766 & 39.5 & 357 & 38.3 & 409 & 40.6 & \\
\hline $70 \%$ or above & 491 & 25.3 & 226 & 24.3 & 265 & 26.3 & \\
\hline Don't Know \# & 144 & 7.4 & 57 & 6.1 & 87 & 8.6 & \\
\hline Declined to Provide this Information & 63 & 3.2 & 32 & 3.4 & 31 & 3.1 & \\
\hline Total & 1940 & & 931 & & 1008 & & \\
\hline
\end{tabular}

* Chi Squared Test for Independence across all response categories (continuity correction applied for $2 \times 2$ tables), $~$ collapsed continuous age variable, ${ }^{* *}$ recoded based on students' reported area of study, \# significant within-variable category differences between male/female proportions based on multiple comparisons with Bonferroni adjustment to $p$-value. 


\subsection{General Health and Body Mass Index [BMI]}

The majority $(78.6 \% n=1667)$ of participants rated their general health as either 'good' or 'very good', $15.8 \%(n=336)$ rated it as 'neither poor nor good' and $5.6 \%(n=118)$ as 'poor/very poor'. Males reported a more favourable perception of their general health than females $[\chi 2(3, n=2121)=20.4$, $p=<0.0005$, Cramer's V $=0.01]$.

Body Mass Index [BMI] calculations $(n=1990)$ classified $11.0 \%$ as 'obese', $27.2 \%$ 'overweight', $58.4 \%$ 'normal weight' and 3.3\% 'underweight'. Absolute BMI values of male students were significantly greater than female values (Md. 24.3 vs. $23.5 \mathrm{~kg} / \mathrm{m}^{2}$ ), $\mathrm{U}=441280.0, \mathrm{z}=-4.18, p<0.0005, \mathrm{r}=0.09$.

There was a statistical association between sex and self-perceived BMI category $[\chi 2(3$, $n=2069)=60.2, p<0.0005$, Cramer's $\mathrm{V}=0.17$ ] with a greater proportion of females classifying themselves as 'overweight' (31.2\% vs. $22.5 \%$ ) or 'obese' (4.1\% vs. $1.9 \%)$ in comparison to males. Figures 1 and 2 depict the sex-stratified distribution of both perceived and calculated BMI categories for those who provided all necessary data. The Kappa measure of agreement value between perceived and calculated BMI categories was $0.41, p<0.0005$ (females: 0.50 , males 0.32 ).

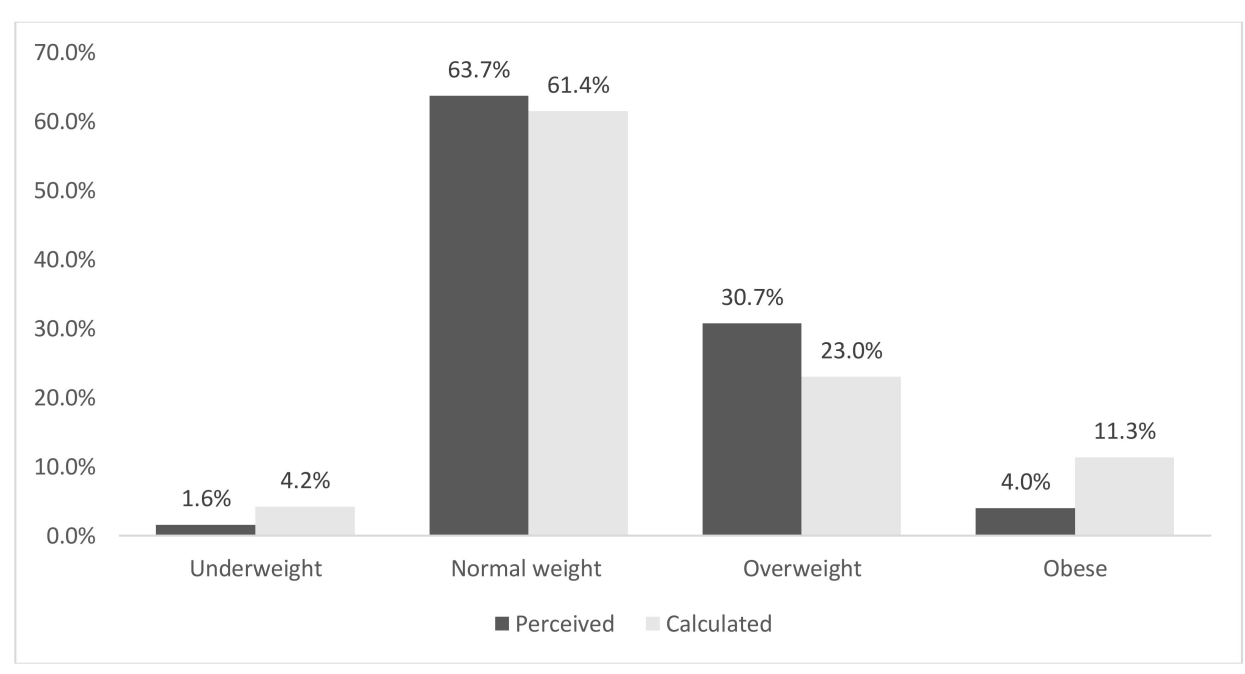

Figure 1. Perceived versus calculated BMI category classifications (females, $n=996$ ). Kappa Measure of Agreement 0.50, $p<0.0005$.

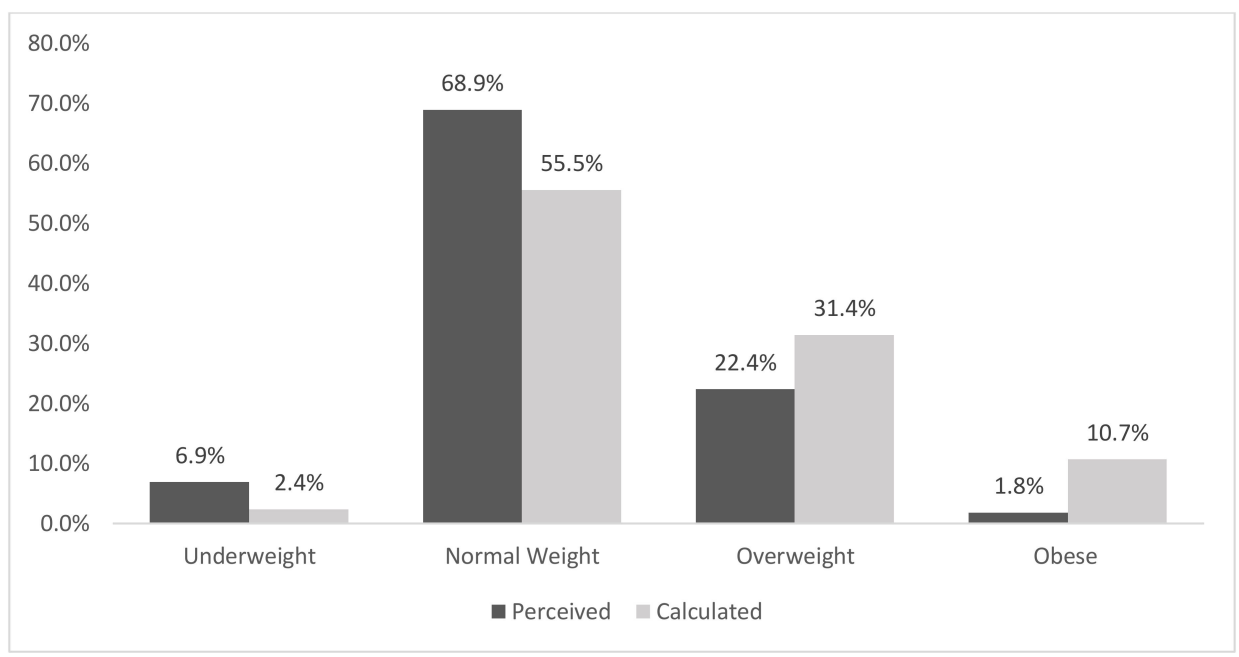

Figure 2. Perceived versus calculated BMI category classifications (males, $n=974$ ). Kappa Measure of Agreement $0.32, p<0.0005$. 


\subsection{Food Habits and Nutrition}

The median number of servings of fruit and vegetables per day was 3.0 (IQR \pm 3.0 ). Females (Mean Rank 1057.33, $n=1046$ ) reported significantly more daily servings than males (Mean Rank 954.75, $n=969, \mathrm{U}=455185.5, \mathrm{z}=-4.01, p<0.0005, \mathrm{r}=0.09)$. In relation to breakfast patterns, $62.2 \%$ $(n=1241)$ reported a habitual breakfast consumption pattern of five weekday mornings (Mon-Fri) and $73.9 \%(n=1466)$ usually consumed breakfast on each of the two weekend mornings (Sat-Sun). There was no significant association between sex and weekday $[\chi 2(5, n=1996)=7.2, p=0.20$, Cramer's $\mathrm{V}=0.06]$ or weekend $\left[\chi^{2}(2, n=1984)=1.9, p=0.39\right.$, Cramer's $\left.\mathrm{V}=0.03\right]$ breakfast consumption.

\subsection{Physical Activity and Sedentary Time}

A significantly greater proportion of males reached the recommended physical activity guidelines during the 7 days prior to data collection $(74.8 \%$ vs. $67.8 \%)[\chi 2(1, n=1480)=8.5, p=0.003$, phi $=-0.08]$. 'Personal exercise/gym activities' were the most commonly reported vigorous physical activities undertaken during this period for both males $(42.7 \%, n=371)$ and females $(38.7 \%, n=354)$. In relation to moderate intensity activities, males most commonly cited 'light jogging' $(40.3 \%, n=350)$ followed by 'walking for transport' $(37.6 \%, n=327)$. The two most popular activities reported by females were 'walking for transport' $(53.6 \%, n=491)$ and 'housework' $(n=48.9 \%, n=448)$.

A lack of time and/or exams/college workload was the most commonly reported barrier to physical activity among both males and females (51.1\% and 52.2\% respectively) as illustrated in Table 2. In relation to sitting time, almost two-thirds reported that they spend at least four hours sitting down during a typical day at college $(65.7 \%, n=1139)$ and this behaviour was independent of sex.

Table 2. Perceived Barriers to Engaging in More Physical Activity and Daily Sitting Time by Sex.

\begin{tabular}{|c|c|c|c|c|c|c|c|}
\hline \multirow{2}{*}{ Physical Activity Variable } & \multicolumn{2}{|c|}{ Total } & \multicolumn{2}{|c|}{$\mathbf{M}$} & \multicolumn{2}{|c|}{$\mathbf{F}$} & \multirow{2}{*}{$p$-Value * } \\
\hline & $n$ & $\%$ & $n$ & $\%$ & $n$ & $\%$ & \\
\hline \multicolumn{8}{|l|}{ Perceived Barriers } \\
\hline No time/workload/exams & 862 & 51.6 & 408 & 51.1 & 454 & 52.2 & $<0.0005$ \\
\hline Already take enough exercise \# & 208 & 12.5 & 122 & 15.3 & 86 & 9.9 & \\
\hline Interested but not willing to spend time & 170 & 10.2 & 85 & 10.6 & 85 & 9.8 & \\
\hline Injury/disability/medical \# condition/pregnancy & 124 & 7.4 & 48 & 6.0 & 76 & 8.7 & \\
\hline Not the sporty type & 93 & 5.6 & 36 & 4.5 & 57 & 6.6 & \\
\hline No access to facilities \# & 65 & 3.9 & 21 & 2.6 & 44 & 5.1 & \\
\hline Not interested & 63 & 3.8 & 30 & 3.8 & 33 & 3.8 & \\
\hline Exercising too much/overtraining \# & 43 & 2.6 & 32 & 4.0 & 11 & 1.3 & \\
\hline Other & 41 & 2.5 & 17 & 2.1 & 24 & 2.8 & \\
\hline Total & 1669 & & 799 & & 870 & & \\
\hline \multicolumn{8}{|l|}{ Sitting time during average day at college (hours) } \\
\hline Less than 1 hour & 25 & 1.4 & 8 & 0.9 & 17 & 1.9 & 0.48 \\
\hline $1-2 \mathrm{~h}$ & 56 & 3.2 & 26 & 3.1 & 30 & 3.4 & \\
\hline $2-3 \mathrm{~h}$ & 163 & 9.4 & 76 & 9.0 & 87 & 9.8 & \\
\hline $3-4 h$ & 351 & 20.2 & 180 & 21.3 & 171 & 19.3 & \\
\hline $4-5 \mathrm{~h}$ & 475 & 27.4 & 227 & 26.8 & 248 & 28.0 & \\
\hline More than $5 \mathrm{~h}$ & 664 & 38.3 & 330 & 39.0 & 334 & 37.7 & \\
\hline Total & 1734 & & 847 & & 887 & & \\
\hline
\end{tabular}

* Chi Squared Test for Independence across all response categories, \# significant within-variable category differences between male/female proportions based on multiple comparisons with Bonferroni adjustment to $p$-value.

\subsection{Alcohol}

The reported age of first alcoholic drink ranged from 9-35 years of age and there were no significant differences between male $(\mathrm{Md} .=16.0, n=718)$ and female $(\mathrm{Md} .=16.0, n=773)$ drinkers in this regard, [U $=274389.0, \mathrm{z}=-0.38 p=0.70 \mathrm{r}=-0.01]$.

To evaluate internal consistency, Cronbach's alpha was calculated for the total AUDIT instrument as well as each sub-domain (Table 3). Males scored significantly higher on the total instrument (Items 1-10: $U=191722.0, p<0.0005)$, as well as the hazardous drinking subscale (Items $1-3: \mathrm{U}=210397.0$, $p<0.0005)$. A breakdown of total and subscale scores by sex is presented in Table 3 below. 
Table 3. Alcohol Use Disorders Identification Test (AUDIT) and sub-domain scores by sex.

\begin{tabular}{|c|c|c|c|c|c|c|c|c|c|}
\hline \multirow{2}{*}{ AUDIT Domain } & \multirow{2}{*}{ Items } & \multirow{2}{*}{ Cronbach's $\alpha$} & \multicolumn{2}{|c|}{ Total } & \multicolumn{2}{|c|}{ Males } & \multicolumn{2}{|c|}{ Females } & \multirow{2}{*}{$p$-Value } \\
\hline & & & $n^{*}$ & Median & $n$ & Median & $n$ & Median & \\
\hline Total AUDIT & $1-10$ & 0.82 & 1329 & 7.0 & 651 & 8.0 & 678 & 7.0 & $<0.0005$ \\
\hline Hazardous Alcohol Use & $1-3$ & 0.66 & 1469 & 5.0 & 707 & 6.0 & 762 & 5.0 & $<0.0005$ \\
\hline Dependence symptoms & $4-6$ & 0.61 & 1430 & 0.0 & 694 & 0.0 & 736 & 0.0 & 0.57 \\
\hline Harmful alcohol use & $7-10$ & 0.68 & 1412 & 2.0 & 683 & 2.00 & 729 & 1.0 & 0.43 \\
\hline
\end{tabular}

* Data presented excludes non-drinkers $(n=182)$ who were not exposed to further items having stated they never drink in item 1. \# Mann Whitney U Test.

With specific reference to the hazardous drinking sub-domain, $54.1 \%$ of females $(n=412)$ and $54.7 \%$ of males $(n=387)$ reached previously applied sex-specific threshold scores ( 6 or more for males and 5 or more for females) [28]. Males reported more frequent episodes of binge drinking [ $\chi 2$ (3, $n=1488)=44.89, p=<0.0005$, Cramer's V $=0.17$ ]. Over half of male drinkers $(52.6 \%, n=377)$ reported engaging in this behaviour on at least a monthly basis in comparison to $41.4 \%(n=319)$ of females. In contrast, the proportion of females who reported that they never binge drink was almost twice that of males ( $21.7 \%$ vs. $10.7 \%)$.

\subsection{Tobacco Smoking and Illicit Substances}

Tobacco smoking (regular or occasional) was less prevalent among males (24.0\% vs. $26.8 \%)$, although this did not reach statistical significance $\left[\chi^{2}(1, n=1607)=1.45, p=0.23\right.$, Phi $\left.=-0.03\right]$. Over half of respondents $57.5 \%(n=906)$ reported using marijuana/cannabis at least once in their lifetime, with $38.6 \%(n=587)$ using in the previous 12 months of the survey and $17.6 \%(n=266)$ in the previous 30 days. There was a significant association between lifetime use and sex, with males generally reporting greater use $\left[\chi^{2}(6, n=1577)=38.97, p=<0.0005\right.$, Cramer's V $\left.=0.16\right]$. Notably, the proportion of males who had used marijuana/cannabis 40 times or more was almost twice the respective proportion of females ( $21.1 \%$ vs. $11.5 \%)$.

With regard to lifetime use of other illicit substances, the most prevalent recreational drug among both sexes was Ecstasy/MDMA (males: 22.9\%, $n=177$; females: 12.8\%, $n=106$ ) followed by Cocaine (males: 19.9\%, $n=153$, females: $10.1 \%, n=84$ ). A significantly greater proportion of males reported lifetime use of Amphetamine (12.6\% vs. 5.9\%), LSD (8.9\% vs. $4.0 \%)$, Cocaine (19.8\% vs. $10.1 \%)$, Ecstasy/MDMA (22.9\% vs. $12.8 \%$ ), Solvents (3.0\% vs. $1.3 \%$ ), Magic Mushrooms (14.0\%vs. $6.8 \%$ ) and Head Shop Products (11.5\% vs. $6.4 \%$ ) as outlined in Figure 3 below.

\subsection{Sexual Health and Behaviours}

The vast majority of students $(87.7 \%, n=1348)$ had been sexually active in the past. Almost $91 \%$ classified themselves as 'heterosexual' $(n=1412), 3.3 \%$ 'homosexual' $(n=52), 4.4 \%$ 'bisexual' $(n=68)$, $1 \%$ 'asexual' $(n=15)$ and a small proportion positioned themselves in the 'other' category. The median age of first intercourse was 17.0 years with no significant difference between males (Md. 17.0, $n=658$ ) and females (Md. 17.0, $n=687$ ) [ $\mathrm{U}=222177.0 \mathrm{z}=-0.55, p=0.58, \mathrm{r}=-0.01]$.

Reported lifetime number of sexual partners ranged from 0 to 350. Males reported a statistically greater number of partners than females (Md. 5.0 vs. 4.0), $\mathrm{U}=181787.0, \mathrm{z}=-4.3, p<0.0005, \mathrm{r}=-0.12$. Just over $6 \%$ of participants $(n=85)$ had been previously told by a doctor that they had a sexually transmitted infection (STI) and there was no significant difference between males and females in this regard $[\chi 2(1, n=1345)=2.2, p=0.14$, phi 0.04]

A significantly greater proportion of females cited having intercourse with one partner as a protective mechanism against STIs $(56.1 \%$ vs. $44.0 \%)$ and expected their partner to have an STI test $(8.0$ vs. $3.6 \%$ ). Males were more likely to have used alcohol/drugs prior to their most recent intercourse $(34.8 \%$ vs. $28.5 \%, p=0.02)$ as outlined in Table 4 . 


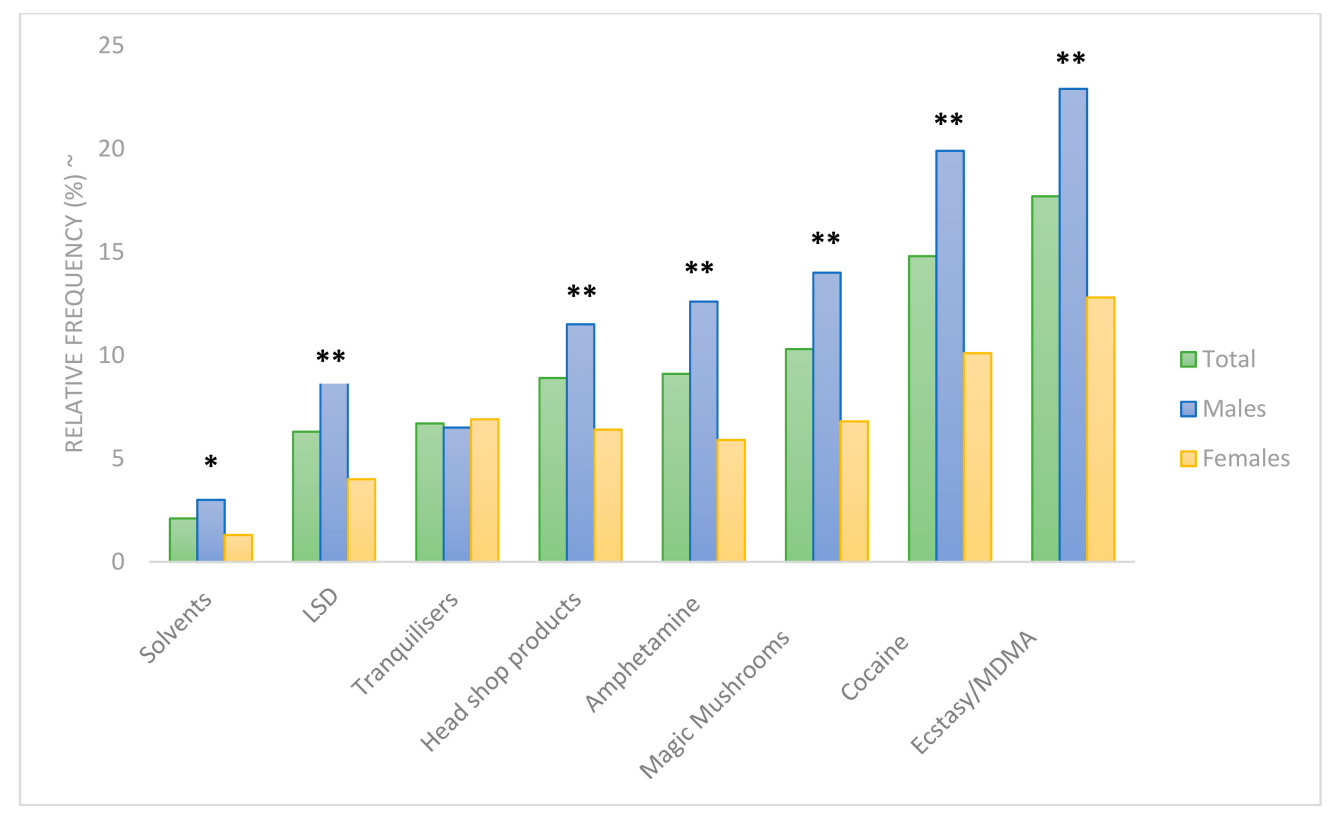

Figure 3. Lifetime use of illicit substances by sex. *significant between sexes $p<0.05{ }^{* *}$ significant between sexes $p<0.0005, \sim$ Item valid responses: Solvents $n=1597, \operatorname{LSD} n=1595$, Tranquilisers $n=1602$, Head Shop Products $n=1598$, Amphetamine $n=1599$, Magic Mushrooms $n=1598$, Cocaine $n=1600$, Ecstasy/MDMA $n=1601$. Due to low absolute numbers reporting their use, relevin, heroin and drugs by injection were omitted from this analysis.

Table 4. Sexual health behaviours: males versus females.

\begin{tabular}{|c|c|c|c|c|}
\hline $\begin{array}{c}\text { 'In What Way Do You Protect Yourself from a Sexually } \\
\text { Transmitted Infection?' (Yes) }\end{array}$ & $\begin{array}{c}\text { Total } \\
(n=1356) \sim\end{array}$ & $\begin{array}{c}\text { Males } \\
(n=659)\end{array}$ & $\begin{array}{l}\text { Females } \\
(n=697)\end{array}$ & $p$-Value * \\
\hline I don't protect myself at all & 6.2 & 6.8 & 5.6 & 0.41 \\
\hline I protect myself by use of a condom & 61.6 & 68.3 & 55.2 & $<0.0005$ \\
\hline I expect my partner to have an STI test & 5.9 & 3.6 & 8.0 & 0.001 \\
\hline Other & 1.4 & 0.8 & 2.0 & 0.08 \\
\hline $\begin{array}{c}\text { ‘Did You Drink Alcohol and/or Use Drugs before You Had } \\
\text { Sexual Intercourse the Last Time?' (Yes/No) }\end{array}$ & $\begin{array}{c}\text { Total } \\
(n=1331)\end{array}$ & $\begin{array}{c}\text { Males } \\
(n=650)\end{array}$ & $\begin{array}{l}\text { Females } \\
(n=681)\end{array}$ & $p$-Value * \\
\hline $\begin{array}{c}\text { ‘Have You (or Your Partner) ever Used the Morning after Pill?' } \\
\text { (Yes/No) }\end{array}$ & $\begin{array}{c}\text { Total } \\
(n=1322)\end{array}$ & $\begin{array}{c}\text { Males } \\
(n=629)\end{array}$ & $\begin{array}{l}\text { Females } \\
(n=693)\end{array}$ & $p$-Value * \\
\hline Yes & 44.4 & 36.7 & 51.4 & $<0.0005$ \\
\hline
\end{tabular}

All figures are percentage values. ${ }^{*}$ Chi Squared Test for Independence $(2 \times 2$ cross tabulation male/female*yes/no).

\subsection{Sleep}

With regard to recent sleep quality $(n=1543), 29.0 \%$ rated this parameter as either 'very poor' $(6.6 \%, n=102)$ or 'poor' $(22.4 \%, n=345), 27.8 \%$ as 'neither poor nor good', $30.6 \%$ as 'good' and $12.6 \%$ as 'very good'. With regard to duration, $79.3 \%(n=1215)$ did not meet the recommended 8-hour threshold during the week (Mon to Fri). There was no significant difference between males and females in terms of perceived sleep quality or reported sleep duration.

\subsection{Mental Wellbeing}

In total, $12.6 \%(n=194)$ rated their overall mental health as either 'very poor' $(2.4 \%)$ or 'poor' $(10.2 \%), 22.6 \%(n=347)$ as 'neither poor nor good', $42.6 \%(n=654)$ as 'good' and $22.1 \%(n=339)$ as 'very good'. Males generally rated their mental health more favourably than females $[\chi 2(4, n=1534)=25.97$, $p=<0.0005$, Cramer's V $=0.13$ ]. Of note, a greater proportion of males rated their health as 'very good' versus females (27.2\% vs. $17.3 \%$ ). Males also scored significantly higher than females (and therefore more favourably from a mental well-being perspective) on both the Energy \& Vitality Index (EVI): [Md. 
50.0, $n=744$ vs. Md. 40.0, $n=788), \mathrm{U}=22064705.0, \mathrm{z}=-8.4, p<0.0005, \mathrm{r}=-0.21]$ and the Mental Health Index-5 (MHI-5): [Md. 68.0, $n=742$ vs. Md. 60.0, $n=789, \mathrm{U}=224799.0, \mathrm{z}=-7.87, p<0.0005$, $\mathrm{r}=0.20$ ]. Table 5 outlines the proportion of male and female students that reported being 'highly stressed' by each respective stressor. A greater proportion of females were highly stressed by all of the listed stressors. Mann Whitney U tests revealed that, for each stressor, MHI- 5 scores were significantly lower (representing greater negative mental health symptoms) among students who reported being 'highly stressed' versus those who did not.

Table 5. Psychological stressors ('highly stressed') by sex and differences in MHI-5 scores between groups.

\begin{tabular}{|c|c|c|c|c|c|c|c|c|}
\hline \multirow[t]{2}{*}{$\begin{array}{l}\text { Psychological Stressor } \\
\text { ('Highly Stressed') }\end{array}$} & \multicolumn{2}{|c|}{ Total } & \multicolumn{2}{|c|}{ Males } & \multicolumn{2}{|c|}{ Females } & \multicolumn{2}{|c|}{$\begin{array}{l}\text { Md. MHI-5 Scores ('Highly Stressed' } \\
\text { vs. other Categories) \# }\end{array}$} \\
\hline & $(n)$ & $\%$ & $(n)$ & $\%$ & $(n)$ & $\%$ & & \\
\hline Exams & 524 & 34.6 & 179 & $24.2^{* * *}$ & 345 & 44.5 & $56.0^{* * *}$ & 68.0 \\
\hline Studies in general & 377 & 24.6 & 122 & $16.4^{* * *}$ & 255 & 32.4 & $50.0^{* * *}$ & 68.0 \\
\hline Financial situation & 352 & 23.1 & 138 & $18.6^{* * *}$ & 214 & 27.2 & $53.5^{* * *}$ & 68.0 \\
\hline Pressure outside of work/college & 290 & 19.4 & 93 & $12.8^{* * *}$ & 197 & 25.7 & $52.0^{* * *}$ & 68.0 \\
\hline Family situation & 141 & 9.3 & 45 & $6.1^{* * *}$ & 96 & 12.3 & $44.0^{* * *}$ & 64.0 \\
\hline Relationships/sexuality & 98 & 6.5 & 38 & 5.2 & 60 & 7.7 & $40.0^{* * *}$ & 64.0 \\
\hline Illness & 68 & 4.5 & 17 & $2.3^{* * *}$ & 51 & 6.6 & $32.0^{* * *}$ & 64.0 \\
\hline Circle of friends & 55 & 3.6 & 18 & $2.5^{*}$ & 37 & 4.7 & $32.0^{* * *}$ & 64.0 \\
\hline Social Media & 33 & 2.2 & 9 & $1.2^{*}$ & 24 & 3.1 & $36.0^{* * *}$ & 64.0 \\
\hline
\end{tabular}

${ }^{* * *} p<0.0005,{ }^{* *} p<0.01,{ }^{*} p<0.05$. \# 'highly stressed' vs. those who selected one of the other categories in the Likert scale ('often stressed', 'not often stressed' or 'never stressed'). 'Other' was excluded from this analysis $(n=20)$.

\subsection{Social Media}

Only $3.6 \%$ of total participants $(n=56)$ did not have a social media account of any kind. The most common platforms reported were Facebook $(93.0 \%, n=1430)$, Snapchat $(69.2 \%, n=1064)$ and Instagram $(54.2 \%, n=833)$. Females were more likely to have a Facebook, Instagram and Snapchat account and males were more likely not to have an active social media account at all (Table 6).

Table 6. Social media platforms by sex.

\begin{tabular}{ccccc}
\hline Social Media Platform & $\begin{array}{c}\text { Total } \\
(\boldsymbol{n}=\mathbf{1 5 3 7 )}\end{array}$ & $\begin{array}{c}\text { Males } \\
(\boldsymbol{n}=\mathbf{7 5 1 )})\end{array}$ & $\begin{array}{c}\text { Females } \\
(\boldsymbol{n}=\mathbf{7 8 6})\end{array}$ & $\boldsymbol{p}$-Value \\
\hline Facebook & 93.0 & 90.3 & 95.7 & $<0.0005$ \\
Snapchat & 69.2 & 64.2 & 74.0 & $<0.0005$ \\
Instagram & 54.2 & 42.7 & 65.1 & $<0.0005$ \\
Twitter & 40.6 & 40.6 & 40.6 & 1.0 \\
LinkedIn & 27.4 & 29.2 & 25.7 & 0.14 \\
No social media account & 3.6 & 5.5 & 1.9 & $<0.0005$ \\
Other & 2.7 & 2.5 & 2.9 & 0.75 \\
\hline
\end{tabular}

All figures are percentage values.

Females were more likely to have posted pictures than males during the 30 days prior to the survey $(73.7 \%$ vs. $57.2 \%),\left[\chi^{2}(1, n=1462)=43.55, p=<0.0005\right.$, Phi $\left.=0.17\right]$. Of those who posted pictures (65.8\% of applicable participants), $44.0 \%(n=425)$ posted pictures of themselves either drinking or being around alcohol. During 'weekdays' (Mon-Fri), 31.6\% $(n=464)$ spent 90 min or more per day on social media and there was no significant difference between males and females in this regard $(30.3 \%$ vs. $32.8 \%),[\chi 2(1, n=1469)=0.99, p=0.32$, phi $=-0.03]$. A significantly greater proportion of females reported spending $90 \mathrm{~min}$ or more on social media per day at the weekend (35.1\% vs. 27.0\%) [ $\chi 2$ (1, $n=1457)=10.66, p=0.001$, phi $=-0.08$ ]. 


\subsection{Predictors of Energy and Vitality Index (EVI) Scores}

Multivariate linear regression was carried out with EVI score as the dependant variable. Independent categorical variables were dichotomised as outlined below. Based on findings outlined above, initial independent variables included as predictors were sex $(0=$ male, $1=$ female $)$, age, having a 'good' or 'very good' general health perception (dichotomised as $0=$ no, $1=$ yes), habitual daily fruit and vegetable servings, adjusted physical activity volume (moderate and vigorous only, as described above), AUDIT-C scores, tobacco smoking $(0=$ no $1=$ yes $)$, lifetime cannabis/marijuana use $(0=$ never or less than 20 times, $1=$ at least 20 times or more), 'good' or 'very good' sleep quality $(0=$ no, $1=$ yes), 'good' or 'very good' mental health perception $(0=$ no, $1=$ yes $)$ using social media for at least 90 min per day Mon-Fri $(0=$ no or not applicable, $1=$ yes $)$, lifetime use of ecstasy $(0=$ no, $1=$ yes $)$, calculated BMI, self-perceived weight category ( $0=$ underweight or normal weight $1=$ overweight/obese), sitting time ( $0=$ up to $4 \mathrm{~h}, 1=4 \mathrm{~h}$ or more) and number of sexual partners. In terms of missing data points due to survey skip logic, non-drinkers $(n=182)$ were included as having an AUDIT-C score of ' 0 ', those not sexually active $(n=189)$ included as having ' 0 ' sexual partners, and those without an active account $(n=56)$ included as spending ' 0 ' daily minutes on social media. Only the independent variables that displayed a statistically significant influence in the initial model were included in the final model (Table 7). This model had an adjusted R-squared value of 0.370 , thus accounting for $37.0 \%$ of the variance in EVI scores.

Table 7. Multiple Linear Regression Model with EVI Scores as the Dependent Variable.

\begin{tabular}{ccc}
\hline Predictor Variable & Standardised $\beta$ & $p$-Value \\
\hline Sex & -0.15 & $<0.0005$ \\
General health rating & 0.15 & $<0.0005$ \\
Daily total fruit and vegetable servings & 0.08 & $<0.0005$ \\
AUDIT-C scores & 0.05 & 0.04 \\
Mental health rating & 0.32 & $<0.0005$ \\
Recent sleep quality & 0.27 & $<0.0005$ \\
Social media 90 min or more on weekdays & -0.06 & 0.01 \\
Perception of being overweight/obese & -0.09 & $<0.0005$ \\
Adjusted R Squared of the Model & 0.370 & $<0.0005$ \\
\hline
\end{tabular}

\section{Discussion}

This study provides an insight into the lifestyle behaviours of students at a Higher Education Institution (HEI) in southern Ireland. In the most recent academic year, there were 231,710 full and part-time enrolments in Irish HEIs, a figure that has consistently increased over the past five years [64]. Therefore, in a time where non-communicable diseases constitute an unprecedented public health challenge, habitual behaviours of this growing cohort are of cross-sectoral interest from the perspective of preserving the health of generations to come [65].

All registered students of the Institute $(n=11,261)$ with a valid student email address were eligible, and provided with an opportunity to participate. This approach was deemed preferable to probabilistic sampling given that the fundamental purpose of this research was to inform an institute-wide campus health promotion initiative (A Healthy CIT). From this perspective, it was essential that all students were provided with an equal opportunity to contribute. Secondly, in-classroom response bias was a concern, due to the smaller class numbers at Cork Institute of Technology relative to many other HEIs. Dissemination via email afforded students the opportunity complete the questionnaire in a more private setting, given the sensitive nature of certain items.

In the absence of comparative literature, the initial response rate (21.2\%) could be perceived as low. However, in terms of the absolute value, the reported sample size was greater than previously-reported values from a multitude of single-HEI studies. In an Irish context, a previous study carried out at National University of Ireland Galway [52] reported a sample size of 841. In addition, although a 
contrasting probabilistic sampling method was employed, a study conducted at University College Cork reported a sample size of 2275 [28]. It should be borne in mind that, in terms of student enrolments, both of these aforementioned HEIs are of a greater magnitude than Cork Institute of Technology. Internationally, in a study of students attending the University of Marburg in Germany [21], a total of 1319 initial responses were received. This study adopted a convenience sampling approach and was logistically restricted to three of the University's Schools [21]. Similarly, convenience sampling was employed in a study conducted at a single UK university where 410 responses to a health and lifestyle questionnaire instrument were received, representing $16 \%$ of the HEI sample [47]. Finally, the current study's response rate is also marginally lower than the response rate $(27 \%, n=985)$ received to a health questionnaire confined to a single campus (Pontevedra) of the University of Vigo in Spain [49]. When contextualised in terms of previous Irish and international work, the sample size of the current study appears to compare favourably in this regard.

Although over three-quarters $(78.6 \%, n=1667)$ of participants rated their health as either 'very good' or 'good'; this is lower than the most recent age-stratified comparative figures from the general Irish population where $93 \%$ of $15-24$ year olds and $94 \%$ of 25-34 year olds rated their general health within these parameters [66]. General health was rated more favourably by males in the current study, which is consistent with previous Irish research [24] as well as an international study involving first year undergraduate students in Sweden [67].

The calculated prevalence of overweight/obesity for male $(n=979)$ and female $(n=1011)$ participants ( $41.9 \%$ and $34.7 \%$ respectively) was greater than previously reported values of $17 \%$ (males) and $6.1 \%$ (females) within a cohort of university students from 22 countries across Europe, North America, Asia and South America [68]. That particular study also highlighted a tendency for students to over-report height and under-report body mass, hence potentially underestimating their overall BMI value [68]. Due to a similar reliance on self-reported data in the current study, the true prevalence of overweight and obesity may be even greater in the present cohort. Given the established association between overweight/obesity and increased relative risk of all-cause mortality on a global scale [69], this is a concerning trend that, if maintained, could result in a plethora of detrimental sequelae in later life [70].

The discrepancy between students' self-perceived and calculated BMI category is also a concern. Although the Kappa measure of agreement, a commonly used indicator of inter-rater reliability, reached statistical significance for these variables (Kappa 0.41, $p<0.0005$ ), in practical terms this may constitute a weak level of agreement according to revised interpretations of this statistic [71]. Level of agreement was lower for males than females $(0.32$ vs. 0.50$)$, which is consistent with findings in a Canadian study [72] but contradictory to findings in a study involving over 34,000 employees of a multi-centre financial company in Japan [73].

Among males, 'underweight' was overestimated by $188 \%$, 'normal weight' overestimated by $24 \%$, 'overweight' underestimated by $29 \%$ and 'obesity' underestimated by $83 \%$. This suggests that, for males, the magnitude of the discrepancy between perceived and calculated BMI is greatest at either very low (underweight) or very high (obese) BMI values and less exaggerated within the normal and overweight categories.

Qualitatively, the following trends were observed among those who provided height/body mass data as well as their self-perceived weight category. Firstly, obesity was underestimated by both females ( $4 \%$ perceived prevalence vs. $11.3 \%$ calculated prevalence) and males ( $1.8 \%$ perceived vs. $10.7 \%$ calculated). However, a greater proportion of females perceived themselves to be overweight relative to the calculated overweight prevalence (30.7\% vs. $23.0 \%$ ). Conversely, only $22.4 \%$ of males perceived themselves as overweight whereas mathematical calculations classified a greater proportion of $31.4 \%$ within this category.

Strong evidence has accumulated to suggest that a significant proportion of those who are overweight or obese either perceive themselves to be of normal weight or fail to recognise the extent of their overweight/obesity due to the 'visual normalisation' of larger body types in contemporary 
society [74]. The findings of the current study align with this trend for both sexes with respect to obesity but only for males regarding overweight. The fact that a greater proportion of females classified themselves as 'overweight' relative to the calculated prevalence could be attributable to the attenuating effect of visual exposure to aesthetically lean body types in popular media targeted towards female cohorts [74]. The tendency of normal or underweight females to categorise themselves as overweight is also consistent with previous research involving university students across seven European countries [16]. This study concluded that, despite concurrent self-reported height/body mass values yielding a normal calculated BMI, females tended to categorise themselves as excessively fat and males perceived themselves as excessively thin [16]. Future mixed-method studies are required to explore sex-specific patterns of discrepant anthropometric perceptions, to determine the reasons for such discrepancies and determine the extent to which the aforementioned 'visual normalisation' of overweight/obesity [74] influences perceptions. Quantitatively, such research should directly compare self-reported, objectively measured and self-perceived BMI within the same population. Qualitatively, potential social mediators of body image perceptions need to be explored.

From a nutritional perspective, daily fruit and vegetable intake was sub-optimal (median 3.0 servings). In Ireland, the Department of Health has recently revised its dietary guidelines for the population, increasing the recommended daily servings of fruit and vegetables to 7 per day [75]. In the current study, only $5.5 \%$ of males and $5.7 \%$ of females habitually achieved this. In terms of absolute values, females reported more daily servings than males, a trend that is consistent with extant literature $[7,21,47]$.

Conversely, a greater proportion of males attained the minimum recommended volume of physical activity during the 7 days prior to respective survey completion $(74.8 \%$ vs. $67.8 \%, p=0.003)$. This substantiates the findings of previous studies that reported a tendency for male students to be more physically active than their female counterparts [24,48,49].

Sitting time was ingrained within the college day, coupled with a perceived lack of time reported as the predominant barrier to physical activity by both sexes. A recent meta-analysis reported that, regardless of physical activity, the risk of death from all causes increased by $2 \%$ for each hour of sitting time per day, with further increases of $5 \%$ for each additional hour of sitting time at or greater than a total of $7 \mathrm{~h}$ per day [76]. HEIs should give consideration to this issue at a macro level whereby the cultural norms of an institution should not intrinsically promote sedentary behaviours. Academic curricula should incorporate, rather than impede, opportunities for students to become more physically active.

The reliability of the AUDIT instrument has been confirmed in a variety of settings $[77,78]$, including a HEI cohort in the USA [79]. The instrument and/or its sub-domains have been utilised internationally to screen for hazardous drinking in HEI student populations $[28,29,31-33,36,80]$. Although hazardous drinking classifications were comparable between sexes ( $54.1 \%$ of females, $54.7 \%$ of males), males scored significantly higher on the AUDIT instrument and engaged in binge drinking more frequently. From a risk stratification perspective, a greater proportion of males ( $34.8 \%$ vs. $28.5 \%$, $p=0.02)$ consumed alcohol and/or used drugs prior to their most recent sexual intercourse. Whilst this relationship requires further investigation, it suggests that male students adopt a riskier attitude when under the influence of alcohol and/or drugs, which could result in impaired decision-making that may impact related lifestyle domains (sexual health for example). In terms of sexual risk-taking, males reported a greater number of lifetime sexual partners and were less likely to expect their partner to take an STI test. Males were more likely to have used a number of recreational substances, including Ecstasy/MDMA (22.9\% vs. $12.8 \%$ ) and Cocaine (19.9\% vs. $10.1 \%$ ) which is consistent with previous literature [24].

Females experienced greater levels of psychological stress and also achieved statistically lower scores (and therefore less favourable) in both the Energy and Vitality Index (EVI) (positive mental health characteristics) and the Mental Health Index- 5 (negative mental health symptoms) measures. This mirrors trends in the general Irish population [81] as well as previously reported trends among HEI students in Ireland [52,82]. 
Of note, mean MHI-5 scores were lower relative to the general Irish population [81] for both females ( 57.9 vs. 81.8 ) and males (65.7 vs. 85.5$)$. This was also the case with EVI mean scores for both sexes (females: 41.8 vs. 65.9 , males: 50.5 vs. 69.8 ). Although a contrasting measurement scale was utilised, this trend has been mirrored internationally in Australian research that reported an $83.9 \%$ prevalence of psychological distress among a sample of 6479 university students relative to a prevalence of $29 \%$ among the general Australian population [83]. Furthermore, research involving 5572 university students from 12 countries across Europe, Asia and North America highlighted a $28.8 \%$ prevalence of suicidal thoughts as well as a $33.6 \%$ prevalence of clinically-relevant psychological distress [84]. Therefore, it is evident that although certain stressors are interwoven within the higher education experience, institutions need to be aware of the significant and measurable detrimental effect that such stressors may be exerting on students' mental health.

Of all self-rated parameters (general health, recent sleep quality, mental health), sleep quality was rated most negatively (29.0\% rated this as either 'very poor' or 'poor'). A substantial body of evidence has accrued in recent years demonstrating an inverse relationship between sub-optimal sleep and academic performance at third level [85-90]. Only one-fifth of students $(20.7 \%, n=318)$ reported getting at least $8 \mathrm{~h}$ sleep on a typical weeknight (Mon-Fri), but a tendency to compensate was observed at weekends with an increased value of $58.3 \%$. This may be due to later bed times and waking times at the weekend, which should be addressed in order to stabilise circadian rhythms and standardise sleep patterns across the week [91].

Although the vast majority of students $(96.4 \%)$ had at least one active social media account, males were more likely not to have any $(5.5 \%$ vs. $1.9 \%, p<0.0005)$. Notably, from Monday to Friday, almost one third who had any active account (31.6\%) spent at least $90 \mathrm{~min}$ or more each day on social media. Using social media while studying could be associated with inadequate time management and disproportionate cramming prior to examinations, as was found in previous Irish research involving a cohort of medical students [62].

The second objective was to identify the significant health and lifestyle predictors of positive mental health, using EVI scores as the dependent variable. Sex was included as an independent variable given the fact that statistically significant differences in EVI scores were revealed by a Mann Whitney $U$ Test as outlined above. A regression equation was derived that accounted for $37.0 \%$ of the variance in EVI scores with no evidence of multi-collinearity between independent variables and a straight line relationship between residuals and predicted EVI scores.

Positive predictors were having a 'good/very good' general health perception, habitual daily fruit and vegetable servings, AUDIT-C scores (items 1-3 of total AUDIT instrument) 'good/very good' mental health rating and 'good/very good' recent sleep quality. Negative predictors were female sex, spending at least $90 \mathrm{~min}$ per day on social media Mon-Fri $(0=$ no, $1=$ yes $)$, and having a perception of being overweight/obese ( $0=$ underweight/normal weight, $1=$ overweight/obese).

It is not surprising that the predictors with the greatest influence on EVI scores were having a positive (good/very good) perception of mental health (standardised $\beta 0.32$ ), recent sleep quality (standardised $\beta$ 0.27) and general health (standardised $\beta$ 0.15). The standardised beta value obtained for AUDIT-C scores however (0.05) suggests that as scores on this subscale measure of hazardous drinking increase, a positive (and therefore more favourable) influence on EVI score is exerted. This relationship could be explained by the fact that alcohol consumption is heavily ingrained within Irish society [92] and appears inextricably linked with the higher education lifestyle [93]. Students who consume alcohol as part of social activities may therefore feel a greater sense of social acceptance and this in turn could enhance their positive mental health. This hypothesis is supported by the work of Capron et al. [80] who acknowledged that for certain students, the immediate benefits, such as social lubrication, may be sought after despite the later cost of negative consequences. A qualitative exploration of this finding would be particularly beneficial to guide the design of cohort-specific alcohol interventions, alternative alcohol-free social activities and institutional policies going forward. 
It is notable that calculated BMI values were not a significant predictor of EVI scores in the initial model, but having a perception of being overweight or obese was a statistically significant negative predictor included in the final model. This should be interpreted in the context of the relatively weak level of agreement between self-perceived and calculated BMI category. In the first instance, there is a requirement to investigate and address the evident discrepancies between calculated BMI versus subjectively perceived, and socially influenced, attitudes towards body habitus. The findings of the current paper provide a definitive rationale for this work given that inaccurate perceptions of overweight/obesity, particularly among female students, may be negatively impacting mental health.

\subsection{Strengths}

The predominant strength is the incorporation of a multitude of health and lifestyle domains within a single study hence facilitating multivariate analysis. Validated scales will facilitate future longitudinal studies as well as a myriad of international comparisons within each health domain. This work also serves to address the paucity of contemporary data pertaining to the lifestyle behaviours of HEI students in Ireland. Pragmatically, this study provides empirical evidence to assist HEIs in terms of resource allocation and strategic prioritisation of health-related domains in light of ongoing funding constraints [51]. Furthermore, at the time of writing, planning of the second phase of A Healthy CIT's programme of research activities has commenced. This phase will involve dissemination of a second iteration of the questionnaire instrument outlined above to enable retrospective comparisons with baseline data described in the current paper.

\subsection{Limitations}

Due to the cross-sectional design employed, associations cannot be deemed causal. Secondly, although all students were eligible to participate, a convenience sample was employed, which potentially introduced a selection bias. Therefore, findings may not be representative of all students of the Institute. As there was an inevitable reliance on self-report data, under/over-reporting, egoism and/or socially desirable responses cannot be ruled out. It is also possible that there was variability in reported lifestyle trends and health metrics between participants who responded to the survey during the initial data collection period (prior to examinations) versus those who responded during the subsequent 7-day period (post examinations). However, any alleged variability should be considered in the context of the semesterised nature of programme delivery at Cork Institute of Technology. An inherent culture of continuous assessment exists within the Institute in order to disperse student workloads more evenly throughout the academic year. Therefore, it is less likely that the end of semester formal examinations would have significantly influenced habitual lifestyle patterns. Finally, the findings of this study may not be entirely generalisable to Irish or international student cohorts, due to inherent cultural differences that exist between HEIs.

\section{Conclusions}

Health and lifestyle behaviours among this cohort were sub-optimal and would benefit from sex-specific multi-level initiatives incorporating institutional policy review. Initial concerns are hazardous drinking behaviours, sub-optimal fruit and vegetable intake, poor sleep quality and stark misperceptions of anthropometric status. Males may adopt riskier attitudes towards alcohol, illicit substances and sexual behaviours, despite more favourable perceptions of general health. Females appear to exhibit greater levels of psychological stress, particularly with regard to academic workload. Future longitudinal studies are required to make inferences regarding causality. Qualitative exploration would be particularly worthwhile to gain a greater understanding of the micro and macro-level mediators of health-related behaviours during this formative stage.

Author Contributions: Conceptualization, A.B., J.D. and C.O.; Methodology, A.B., J.D. and C.O.; Formal analysis, A.B.; Investigation, A.B.; Data curation, A.B.; Writing-Original draft preparation, A.B.; Writing-Review and editing, A.B., J.D. and C.O.; Visualization, A.B.; Supervision, C.O. and J.D.; Project administration, A.B. 
Funding: This research received no external funding.

Conflicts of Interest: The authors declare no conflict of interest.

\section{References}

1. World Health Organisation (WHO). Global Status Report on Non Communicable Diseases 2014; WHO: Geneva, Switzerland, 2014.

2. World Health Organisation (WHO). Non Communicable Diseases Country Profiles 2018; CC BY NC-SA 3.0 IGO; WHO: Geneva, Switzerland, 2018.

3. Department of Health. Healthy Ireland. A Framework for Improved Health and Wellbeing. 2013-2025. Dublin. 2013. Available online: https://health.gov.ie/wp-content/uploads/2014/03/ HealthyIrelandBrochureWA2.pdf (accessed on 9 September 2019).

4. Wang, D.; Ou, C.Q.; Chen, M.Y.; Duan, N. Health-promoting lifestyles of university students in mainland China. BMC Public Health 2009, 9, 379. [CrossRef] [PubMed]

5. Hunt, J.; Eisenberg, D. Mental health problems and help-seeking behavior among college students. J. Adolesc. Health 2010, 46, 3-10. [CrossRef]

6. El Ansari, W.; Stock, C.; Snelgrove, S.; Hu, X.; Parke, S.; Davies, S.; John, J.; Adetunji, H.; Stoate, M.; Deeny, P.; et al. Feeling healthy? A survey of physical and psychological wellbeing of students from seven universities in the UK. Int. J. Environ. Res. Public Health 2011, 8, 1308-1323. [CrossRef] [PubMed]

7. El Ansari, W.; Stock, C.; John, J.; Deeny, P.; Phillips, C.; Snelgrove, S.; Adetunji, H.; Hu, X.; Parke, S.; Stoate, M.; et al. Health promoting behaviours and lifestyle characteristics of students at seven universities in the UK. Cent. Eur. J. Public Health 2011, 19, 197-204. [CrossRef]

8. Hoffman, D.J.; Policastro, P.; Quick, V.; Lee, S.K. Changes in body weight and fat mass of men and women in the first year of college: A study of the "freshman 15". J. Am. Coll. Health 2006, 55, 41-45. [CrossRef]

9. Vadeboncoeur, C.; Townsend, N.; Foster, C. A meta-analysis of weight gain in first year university students: Is freshman 15 a myth? BMC Obes. 2015, 2, 22. [CrossRef]

10. De Vos, P.; Hanck, C.; Neisingh, M.; Prak, D.; Groen, H.; Faas, M.M. Weight gain in freshman college students and perceived health. Prev. Med. Rep. 2015, 2, 229-234. [CrossRef]

11. Bodenlos, J.S.; Gengarelly, K.; Smith, R. Gender differences in freshmen weight gain. Eat. Behav. 2015, 19, 1-4. [CrossRef]

12. Kelly, M.C.; Latner, J.D. Evaluating patterns of weight and body composition change among college women. Eat. Behav. 2015, 17, 157-162. [CrossRef]

13. Finlayson, G.; Higgs, C.J.; Hill, A.; Hetherington, M. Susceptibility to weight gain. Eating behaviour traits and physical activity as predictors of weight gain during the first year of university. Appetite 2012, 58, 1091-1098. [CrossRef]

14. Serlachius, A.; Hamer, M.; Wardle, J. Stress and weight change in university students in the United Kingdom. Physiol. Behav. 2007, 92, 548-553. [CrossRef] [PubMed]

15. Gropper, S.S.; Simmons, K.P.; Connell, L.J.; Ulrich, P.V. Changes in body weight, composition, and shape: A 4-year study of college students. Appl. Physiol. Nutr. Metab. 2012, 37, 1118-1123. [CrossRef] [PubMed]

16. Mikolajczyk, R.T.; Maxwell, A.E.; El Ansari, W.; Stock, C.; Petkeviciene, J.; Guillen-Grima, F. Relationship between perceived body weight and body mass index based on self- reported height and weight among university students: A cross-sectional study in seven European countries. BMC Public Health 2010, 10, 40. [CrossRef]

17. Hilger, J.; Loerbroks, A.; Diehl, K. Eating behaviour of university students in Germany: Dietary intake, barriers to healthy eating and changes in eating behaviour since the time of matriculation. Appetite 2017, 109, 100-107. [CrossRef]

18. Opoku-Acheampong, A.A.; Kidd, T.; Adhikari, K.; Muturi, N.; Kattelmann, K. Assessing physical activity, fruit, vegetable, and sugar-sweetened beverage intake patterns of college students in Kansas. J. Nutr. Educ. Behav. 2018, 50, 977-983. [CrossRef]

19. Unusan, N. Linkage between stress and fruit and vegetable intake among university students: An empirical analysis on Turkish students. Nutr. Res. 2006, 26, 385-390. [CrossRef]

20. Papadaki, A.; Hondros, G.; Scott, J.; Kapsokefalou, M. Eating habits of University students living at, or away from home in Greece. Appetite 2007, 49, 169-176. [CrossRef] 
21. Keller, S.; Maddock, J.E.; Hannöver, W.; Thyrian, J.R.; Basler, H.D. Multiple health risk behaviors in German first year university students. Prev. Med. 2008, 46, 189-195. [CrossRef]

22. Morse, K.L.; Driskell, J.A. Observed sex differences in fast-food consumption and nutrition self-assessments and beliefs of college students. Nutr. Res. 2009, 29, 173-179. [CrossRef]

23. Driskell, J.A.; Meckna, B.R.; Scales, N.E. Differences exist in the eating habits of university men and women at fast-food restaurants. Nutr. Res. 2006, 26, 524-530. [CrossRef]

24. Hope, A.; Dring, C.; Dring, J. The Health of Irish Students: College Lifestyle and Attitudinal National (CLAN) Survey; Department of Health and Children: Dublin, Ireland, 2005.

25. Nelson, M.C.; Lust, K.; Story, M.; Ehlinger, E. Credit card debt, stress and key health risk behaviors among college students. Am. J. Health Promot. 2008, 22, 400-406. [CrossRef] [PubMed]

26. Diehl, K.; Hilger, J. Physical activity and the transition from school to university: A cross-sectional survey among university students in Germany. Sci. Sport 2016, 31, 223-226. [CrossRef]

27. LaCaille, L.J.; Dauner, K.N.; Krambeer, R.J.; Pedersen, J. Psychosocial and environmental determinants of eating behaviors, physical activity, and weight change among college students: A qualitative analysis. J. Am. Coll. Health 2011, 59, 531-538. [CrossRef] [PubMed]

28. Davoren, M.P.; Shiely, F.; Byrne, M.; Perry, I.J. Hazardous alcohol consumption among university students in Ireland: A cross-sectional study. BMJ Open 2015, 5, e006045. [CrossRef] [PubMed]

29. Heather, N.; Partington, S.; Partington, E.; Longstaff, F.; Allsop, S.; Jankowski, M.; Wareham, H.; St Clair Gibson, A. Alcohol use disorders and hazardous drinking among undergraduates at English universities. Alcohol. Alcohol. 2011, 46, 270-277. [CrossRef]

30. Bewick, B.M.; Mulhern, B.; Barkham, M.; Trusler, K.; Hill, A.J.; Stiles, W.B. Changes in undergraduate student alcohol consumption as they progress through university. BMC Public Health 2008, 8, 163. [CrossRef]

31. Lannoy, S.; Billieux, J.; Poncin, M.; Maurage, P. Binging at the campus: Motivations and impulsivity influence binge drinking profiles in university students. Psychiatry Res. 2017, 250, 146-154. [CrossRef]

32. Hallett, J.; Howat, P.M.; Maycock, B.R.; McManus, A.; Kypri, K.; Dhaliwal, S.S. Undergraduate student drinking and related harms at an Australian university: Web-based survey of a large random sample. BMC Public Health 2012, 12, 37. [CrossRef]

33. Connor, J.; Gray, A.; Kypri, K. Drinking history, current drinking and problematic sexual experiences among university students. Aust. N. Z. J. Public Health 2010, 34, 487-494. [CrossRef]

34. Kypri, K.; Langley, J.D.; McGee, R.; Saunders, J.B.; Williams, S. High prevalence persistent hazardous drinking among New Zealand tertiary students. Alcohol. Alcohol. 2002, 37, 457-464. [CrossRef]

35. Zakletskaia, L.; Wilson, E.; Fleming, M.F. Alcohol Use in Students Seeking Primary Care Treatment at University Health Services. J. Am. Coll. Health 2010, 59, 217-223. [CrossRef] [PubMed]

36. Maphisa, J.M.; Young, C. Risk of alcohol use disorder among South African university students: The role of drinking motives. Addict. Behav. 2018, 82, 44-49. [CrossRef] [PubMed]

37. Quintela, O.; Bermejo, A.M.; Tabernero, M.J.; Strano-Rossi, S.; Chiarotti, M.; Lucas, A.C. Evaluation of cocaine, amphetamines and cannabis use in university students through hair analysis: Preliminary results. Forensic Sci. Int. 2000, 107, 273-279. [CrossRef]

38. Bennett, T.; Holloway, K. Motives for illicit prescription drug use among university students: A systematic review and meta-analysis. Int. J. Drug Policy 2017, 44, 12-22. [CrossRef]

39. Downing-Matibag, T.M.; Geisinger, B. Hooking up and sexual risk taking among college students: A health belief model perspective. Qual. Health Res. 2009, 19, 1196-1209. [CrossRef]

40. Beiter, R.; Nash, R.; McCrady, M.; Rhoades, D.; Linscomb, M.; Clarahan, M.; Sammut, S. The prevalence and correlates of depression, anxiety, and stress in a sample of college students. J. Affect. Disord. 2015, 173, 90-96. [CrossRef]

41. Becker, S.P.; Jarrett, M.A.; Luebbe, A.M.; Garner, A.A.; Burns, G.L.; Kofler, M.J. Sleep in a large, multi-university sample of college students: Sleep problem prevalence, sex differences, and mental health correlates. Sleep Health 2018, 4, 174-181. [CrossRef]

42. Barone, T.L. "Sleep is on the back burner": Working students and sleep. Soc. Sci. J. 2017, 54, $159-167$. [CrossRef]

43. Demirci, K.; Akgönül, M.; Akpinar, A. Relationship of smartphone use severity with sleep quality, depression, and anxiety in university students. J. Behav. Addict. 2015, 4, 85-92. [CrossRef] 
44. Orsal, O.; Orsal, O.; Unsal, A.; Ozalp, S.S. Evaluation of internet addiction and depression among university students. Procedia Soc. Behav. Sci. 2013, 82, 445-454. [CrossRef]

45. Moreno, M.A.; Whitehill, J.M. Influence of social media on alcohol use in adolescents and young adults. Alcohol. Res. 2014, 36, 91. [PubMed]

46. Moreno, M.A.; D'Angelo, J.; Whitehill, J. Social media and alcohol: Summary of research, intervention ideas and future study directions. Media Commun. 2016, 4, 50-59. [CrossRef]

47. Dodd, L.J.; Al-Nakeeb, Y.; Nevill, A.; Forshaw, M.J. Lifestyle risk factors of students: A cluster analytical approach. Prev. Med. 2010, 51, 73-77. [CrossRef]

48. Moreno-Gómez, C.; Romaguera-Bosch, D.; Tauler-Riera, P.; Bennasar-Veny, M.; Pericas-Beltran, J.; Martinez-Andreu, S.; Aguilo-Pons, A. Clustering of lifestyle factors in Spanish university students: The relationship between smoking, alcohol consumption, physical activity and diet quality. Public Health Nutr. 2012, 15, 2131-2139. [CrossRef]

49. Varela-Mato, V.; Cancela, J.M.; Ayan, C.; Martin, V.; Molina, A. Lifestyle and health among Spanish university students: Differences by gender and academic discipline. Int. J. Environ. Res. Public Health 2012, 9, 2728-2741. [CrossRef]

50. Okanagan Charter: An International Charter for Health Promoting Universities \& Colleges. 2015. Available online: https://internationalhealthycampuses2015.sites.olt.ubc.ca/files/2016/01/Okanagan-CharterJanuary13v2.pdf (accessed on 12 September 2019).

51. Bickerdike, A.; Dinneen, J.; O'Neill, C. 'A Healthy CIT': A case study outlining the initial development of a campus health promotion initiative in an Irish higher education setting. In Proceedings of the Smart Cities in Smart Regions Conference, Finland University of Applied Sciences, Lahti, Finland, 26-27 September 2018; Aarrevaara, E., Harjapää, A., Eds.; Lahti University of Applied Sciences: Lahti, Finland, 2018.

52. Mac Neela, P.; Dring, C.; Van Lente, E.; Place, C.; Dring, J.; Mc Caffrey, J. Health and Wellbeing of NUI Galway Undergraduate Students: The Student Lifestyle Survey; NUIG Galway: Galway, Ireland, 2012.

53. Mac Neela, P. Personal communication; NUI Galway: Galway, Ireland, 2015.

54. Morgan, K.; McGee, H.; Watson, D.; Perry, I.; Barry, M.; Shelley, E.; Harrington, J.; Molcho, M.; Layte, R.; Tully, N.; et al. SLAN 2007: Survey of Lifestyle, Attitudes \& Nutrition in Ireland: Main Report; Department of Health and Children: Dublin, Ireland, 2008.

55. Body Mass Index-BMI. Available online: http:/www.euro.who.int/en/health-topics/disease-prevention/ nutrition/a-healthy-lifestyle/body-mass-index-bmi (accessed on 12 September 2019).

56. Craig, C.L.; Marshall, A.L.; Sjöström, M.; Bauman, A.E.; Booth, M.L.; Ainsworth, B.E.; Pratt, M.; Ekelund, U.; Yngve, A.; Sallis, J.F.; et al. International physical activity questionnaire: 12-country reliability and validity. Med. Sci. Sports Exerc. 2003, 35, 1381-1395. [CrossRef]

57. Department of Health \& Children; Health Service Executive. The National Guidelines on Physical Activity for Ireland; Dept Health \& Health Service Executive: Dublin, Ireland, 2009.

58. Sport Ireland; IPSOS MRBI. Irish Sports Monitor 2015 Annual Report; Sport Ireland: Dublin, Ireland, 2015.

59. Babor, T.F.; Higgins-Biddle, J.C.; Saunders, J.B.; Monteiro, M.G. The Alcohol Use Disorders Identification Test. Guidelines for Use in Primary Care; WHO: Geneva, Switzerland, 2001.

60. Ware, J.; Snoww, K.K.; Kosinksi, M.A.; Gandek, B.G. SF-36 Health Survey: Manual and Interpretation Guide; Quality Metric, Inc.: Lincoln, RI, USA, 1993.

61. Buysse, D.J.; Reynolds, C.F.; Monk, T.H.; Berman, S.R.; Kupfer, D.J. The Pittsburgh Sleep Quality Index: A new instrument for psychiatric practice and research. Psychiatry Res 1989, 28, 193-213. [CrossRef]

62. Bickerdike, A.; Deasmhunaigh, C.; O'Flynn, S.; O'Tuathaigh, C. Learning strategies, study habits and social networking activity of undergraduate medical students. Int. J. Med. Educ. 2016, 7, 230-236. [CrossRef]

63. Kunttu, K.; Pesonen, T. Student Health Survey 2012: A National Survey among Finnish University Students; Finnish Student Health Service: Helsinki, Finland, 2013.

64. Key Facts and Figures for 2017/18. Available online: https://hea.ie/statistics/data_visualisations/infographics/ (accessed on 22 August 2019).

65. Lee, R.L.; Loke, A.J. Health-promoting behaviors and psychosocial well-being of university students in Hong Kong. Public Health Nurs. 2005, 22, 209-220. [CrossRef]

66. IPSOS MRBI; Dept of Health. Healthy Ireland Survey 2018 Summary of Findings; Stationery Office: Dublin, Ireland, 2018. Available online: https://health.gov.ie/wp-content/uploads/2018/10/Healthy-Ireland-Survey2018.pdf (accessed on 12 September 2019). 
67. Vaez, M.; Laflamme, L. Health behaviors, self-rated health, and quality of life: A study among first-year Swedish university students. J. Am. Coll. Health 2003, 51, 156. [CrossRef]

68. Wardle, J.; Haase, A.M.; Steptoe, A. Body image and weight control in young adults: International comparisons in university students from 22 countries. Int. J. Obes. 2006, 30, 644-651. [CrossRef] [PubMed]

69. Di Angelantonio, E.; Bhupathiraju, S.N.; Wormser, D.; Gao, P.; Kaptoge, S.; Berrington de Gonzalez, A.; Cairns, B.J.; Huxley, R.; Jackson, ChL.; Joshy, G.; et al. Body-mass index and all-cause mortality: Individual-participant-data meta-analysis of 239 prospective studies in four continents. Lancet 2016, 388, 776-786. [CrossRef]

70. Finer, N. Medical consequences of obesity. Medicine 2015, 43, 88-93. [CrossRef]

71. McHugh, M.L. Interrater reliability: The kappa statistic. Biochem. Med. 2012, 22, 276-282. [CrossRef]

72. Herman, K.M.; Hopman, W.M.; Rosenberg, M.W. Self-rated health and life satisfaction among Canadian adults: Associations of perceived weight status versus BMI. Qual. Life Res. 2013, 22, 2693-2705. [CrossRef] [PubMed]

73. Inoue, M.; Toyokawa, S.; Miyoshi, Y.; Miyano, Y.; Suzuki, T.; Suyama, Y.; Inoue, K.; Kobayashi, Y. Degree of agreement between weight perception and body mass index of Japanese workers: MY Health Up Study. J. Occup. Health 2007, 49, 376-381. [CrossRef] [PubMed]

74. Robinson, E. Overweight but unseen: A review of the underestimation of weight status and a visual normalization theory. Obes. Rev. 2017, 18, 1200-1209. [CrossRef]

75. Healthy Food for Life. Available online: https://www.hse.ie/eng/about/who/healthwellbeing/ourpriority-programmes/heal/food-pyramid-images/foodforlifefoodpyramidrationale2016.pdf (accessed on 12 September 2019).

76. Chau, J.Y.; Grunseit, A.C.; Chey, T.; Stamatakis, E.; Brown, W.J.; Matthews, C.E.; Bauman, A.E.; van der Ploeg, H.P. Daily sitting time and all-cause mortality: A meta-analysis. PLoS ONE 2013, 8, e80000. [CrossRef]

77. Reinert, D.F.; Allen, J.P. The alcohol use disorders identification test: An update of research findings. Alcohol. Clin. Exp. Res. 2007, 31, 185-199. [CrossRef]

78. De Meneses-Gaya, C.; Zuardi, A.; Loureiro, S.R.; Crippa, J.A.S. Alcohol Use Disorders Identification Test (AUDIT): An updated systematic review of psychometric properties. Psychol. Neurosci. 2009, 2, 83-97. [CrossRef]

79. Kokotailo, P.K.; Egan, J.; Gangnon, R.; Brown, D.; Mundt, M.; Fleming, M. Validity of the alcohol use disorders identification test in college students. Alcohol. Clin. Exp. Res. 2004, 28, 914-920. [CrossRef] [PubMed]

80. Capron, D.W.; Schmidt, N.B. Positive drinking consequences among hazardous drinking college students. Addict. Behav. 2012, 37, 663-667. [CrossRef] [PubMed]

81. IPSOS MRBI; Dept of Health. Healthy Ireland Survey 2016 Summary of Findings; Stationery Office: Dublin, Ireland, 2016. Available online: https://health.gov.ie/wp-content/uploads/2016/10/Healthy-Ireland-Survey2016-Summary-Findings.pdf (accessed on 12 September 2019).

82. Houghton, F.; Keane, N.; Murphy, N.; Houghton, S.; Dunne, C. Tertiary level students and the mental health index (MHI-5) in Ireland. Irish J. Appl. Soc. Stud. 2011, 10, 7. [CrossRef]

83. Stallman, H.M. Psychological distress in university students: A comparison with general population data. Aust. Psychol. 2010, 45, 249-257. [CrossRef]

84. Eskin, M.; Sun, J.M.; Abuidhail, J.; Yoshimasu, K.; Kujan, O.; Janghorbani, M.; Flood, C.; Carta, M.G.; Tran, U.S.; Mechri, A.; et al. Suicidal behavior and psychological distress in university students: A 12-nation study. Arch. Suicide Res. 2016, 20, 369-388. [CrossRef] [PubMed]

85. Hayley, A.C.; Sivertsen, B.; Hysing, M.; Vedaa, Ø.; Øverland, S. Sleep difficulties and academic performance in Norwegian higher education students. Br. J. Educ. Psychol. 2017, 87, 722-737. [CrossRef]

86. Önder, İ.; Beşoluk, Ş.; İskender, M.; Masal, E.; Demirhan, E. Circadian preferences, sleep quality and sleep patterns, personality, academic motivation and academic achievement of university students. Learn. Individ. Differ. 2014, 32, 184-192. [CrossRef]

87. Flueckiger, L.; Roselind, L.; Meyer, A.H.; Mata, J. How health behaviors relate to academic performance via affect: An intensive longitudinal study. PLoS ONE 2014, 9, e0111080. [CrossRef]

88. Ahrberg, K.; Dresler, M.; Niedermaier, S.; Steiger, A.; Genzel, L. The interaction between sleep quality and academic performance. J. Psychiatr. Res. 2012, 46, 1618-1622. [CrossRef]

89. Abdulghani, H.M.; Alrowais, N.A.; Bin-Saad, N.S.; Al-Subaie, N.M.; Haji, A.M.; Alhaqwi, A.I. Sleep disorder among medical students: Relationship to their academic performance. Med. Teach. 2012, 34,37-41. [CrossRef] 
90. Gilbert, S.P.; Weaver, C.C. Sleep quality and academic performance in university students: A wake-up call for college psychologists. J. Coll. Stud. Psychother. 2010, 24, 295-306. [CrossRef]

91. Forquer, L.M.; Camden, A.E.; Gabriau, K.M.; Johnson, C.M. Sleep patterns of college students at a public university. J. Am. Coll. Health 2008, 56, 563-565. [CrossRef] [PubMed]

92. Mongan, D.; Long, J. Overview of Alcohol Consumption, Alcohol-Related Harm and Alcohol Policy in Ireland; HRB Overview Series 10; HRB: Dublin, Ireland, 2016.

93. Davoren, M.P.; Demant, J.; Shiely, F.; Perry, I.J. Alcohol consumption among university students in Ireland and the United Kingdom from 2002 to 2014: A systematic review. BMC Public Health 2016, 16, 173. [CrossRef] [PubMed]

(C) 2019 by the authors. Licensee MDPI, Basel, Switzerland. This article is an open access article distributed under the terms and conditions of the Creative Commons Attribution (CC BY) license (http://creativecommons.org/licenses/by/4.0/). 